www.jmscr.igmpublication.org Impact Factor 5.244

Index Copernicus Value: 5.88

ISSN (e)-2347-176x ISSN (p) 2455-0450

crossref DOI: http://dx.doi.org/10.18535/jmscr/v4i5.41

Journal Of Medical Science And Clinical Research

\title{
Facie a la Psychologist
}

\section{Authors \\ Dr Munawwar Husain ${ }^{1}$, Hena Fatma ${ }^{2}$}

${ }^{1}$ MBBS, MD, DNB, MNAMS, PG Dip in Criminology and Criminal Administration, Professor, Fmr Medical Superintendent \& Principal, School of Nursing, Department of Forensic Medicine, Aligarh Muslim University, Aligarh, India

${ }^{2} \mathrm{Ph} . \mathrm{D}$ (Scholar), MA (Clinical Psychology), PG Dip in Criminology and Criminal Administration, Research Scholar, Department of Psychology, Aligarh Muslim University, Aligarh, India

Corresponding Author

Munawwar Husain

Email: husain_uia@yahoo.co.in, Mobile No.: 9997497939

\begin{abstract}
As clinical psychologist foraying in to charted as well as uncharted recesses of mind we found that to be a successful practitioner of psychology one has to absorb all configurationally plausible entities that may finally go to construct a successful counseling. The job of a clinical psychologist is not easy. It is laden with uncertainties. Success is elusive. All the applause is collected by the psychiatrist. The travail of the discipline is that it is seldom practiced alone and rarely do they collect the medal of appreciation.

Keywords: facie, clinical psychologist, counseling, empathy, insight
\end{abstract}

\section{Background}

Nevertheless, there is no reason to bow down to frustration and play the second fiddle. The effort should be to stand out amongst the melee of other practitioners of medicine. It is the patient the psychologist must focus on. To satisfy the cravings of mentally ill person, tranquillize him or her with the meaning of purposeful life and that should be the craftsmanship of clinical formulation of unseen psychology.

\section{Need for creating profile of a clinical psychologist}

Several studies have been done focusing on the personality of the psychologist highlighting on few aspects of personality traits to help the patients and themselves too. It is postulated that the psychologist "must possess strong communication skills, including strength in verbal and non-verbal communication"' . In addition they "must possess a high degree of emotional intelligence, including facets of social awareness, self-awareness, self-management and relationship management ${ }^{2}$. Thereby effectively reducing "selfburn-out and their own stress ${ }^{3}$.

Facie a la psychologist - creation of this concept and attempt to gather the feature that would go to make such an appearance is the attempt rendered in this paper. Help of descriptive analogy is liberally undertaken to impress upon the mind of 
seasoned practitioners as well as students of this discipline aiming to broad base this concept. Ultimately if accepted it would be bi-pronged lick - one to shape the personality of the self in order to unconsciously assume the face of the psychologist, and secondly to silently invade the deep recesses of the patient's mind to explore inadequacies and come out with reasoned and non-camouflaged prospect of cure.

\section{Facie a la psychologist}

$\mathbf{f}=$ facial creases fundamentals to be strong

$\mathbf{a}=$ angel's aura attitude

c=compassion

i=insight

$\mathbf{e}=$ empathy

$\mathbf{h}=$ humaneness

$\mathbf{e}=$ enlivened

$\mathbf{n}=$ never saying nay

$\mathbf{a}=$ attentive

These mnemonics are created for easy understanding and recall.

If we were to construct a face of a clinical psychologist who would inspire confidence and yearning to obey him/her in the heart of the patient, I would summarize the facie hena in the following construct i.e., 'it' the neutral composition may not be attractive, therefore the authors have taken the liberty to indulge 'her' as the verb.

"An honest face liberally sprinkled with humaneness, compassion, bursting with empathy and circling angel's aura around the facial creases fundamentally strong enough to guide the patient to an honest and enlivened insight in to the 'self' eliminating in the process the neutralizing feeling of hopelessness and helplessness within the patient and alleviating the strong dejected feeling of 'never'."
For all practical purposes these virtues and qualities would be an amalgamation of all entities featuring in to facial profile of the psychologist. The interaction should be seamless with pulsating cascades of intermingling emotions from both the sides. This is how magical cauldron would be formed out of which the genie of mutual love and respect shall emerge.

\section{Conclusion}

Concluding the discourse the authors feel that this broad description would certainly match the profile of the psychologist. Still the arena is open and would welcome any suggestion or addition to the broad profile thus created.

\section{References}

1. Baharvand, V. (2012): Assessing characteristics of clinical psychology for effective counseling. Life Sci J, 9: 487-490.

2. Bradberry, T. \& Greaves, J. (2009): Emotional intelligence 2.0. San Diego, CA: TalentSmart

3. Clinical Psychologist Profile-Carleton University Accessed at: carleton.ca/ psychology/wp-content/uploads/clinicalpsychologist.pdf Accessed on: 4 May 2016. 